SSCM T

Journal of Sustainable Construction Materials and Technologies
Journal of Sustainable Construction Materials and Technologies

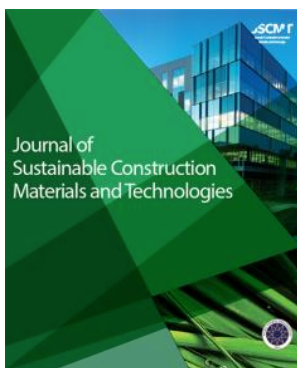

e-ISSN: 2458-973X

https://jscmt.org/

Review Article

\title{
Pollution Free and Sustainable Copper Production Using Greenhouse $\mathrm{CO}_{2}$
}

\author{
Subir Paul ${ }^{\mathrm{a}, *, \odot, \text { Ramesh Chandra Das }}{ }^{\mathrm{a}, \odot}$, Tamal Das $^{\mathrm{a},(0)}$ \\ ${ }^{a}$ Department of Metallurgical and Material Engineering, Jadavpur University, Kolkata, India
}

\begin{abstract}
The objectives of the present investigation to decrease the global pollution by utilizing the $\mathrm{CO}_{2}$ gas, in an effective way to produce the valuable metal copper, using low grade $\mathrm{Cu}$ ore which is termed as waste and not used for conventional $\mathrm{Cu}$ production. So the idea being waste and polluting waste are converted to useful products which will create employment, boost economy and reduce environment pollution. It is an innovative scheme for start-up. Carbonic acid produced by dissolving greenhouse gas $\mathrm{CO}_{2}$ was used for leaching low grade chalcopyrite ore under oxidizing condition. It is a single stage process with a single reactor where combined hydrometallurgical and electrometallurgical process occur. At anode an oxidizing condition is produced by dragging electron thereby increasing the rate of hydrometallurgical extraction producing $\mathrm{Cu}^{++}$from $\mathrm{CuFeS}_{2}$. This generated $\mathrm{Cu}^{++}$is simultaneously deposited at the cathode in the same reactor. The $\mathrm{Cu}$ produced was analysed and identified by RDR. The electrical power and energy consumption were computed. In the conventional cu extraction process from $\mathrm{CuFeS}_{2}$, sulphur come out as $\mathrm{SO}_{2}$, the harmful polluting gas, in contrast in this process, sulphur came out as elemental sulphur and can be sold as by-product.
\end{abstract}

Keywords: Greenhouse Gas; Global Pollution; Sustainable Development; Cu Production; Hydrometallurgy

\section{Introduction}

Global environment pollution is due to the emission waste gases of burnt fuels from automobiles and manufacturing industries. Of these gases, Carbon dioxide is the main pollutant and is cause of global warming. In the developed countries, many industries had to be stopped due to government stringent laws against emission of the polluting $\mathrm{CO}_{2}$. All nations in the developed and developing countries are involved and global pollution affected by one nation may be cause of gas emission of another nation. For over a century and half, such activities have pumped huge $\mathrm{CO}_{2}$. into the atmosphere to increase its level higher than what have been for thousands of years. Though, governments of some pollution worried countries are taking measures to limit emissions of carbon dioxide and other greenhouse gases, the other countries are still emitting the harmful gases. It needs meeting of different nations and forming common laws to combat the problem. Thus, a voluntary agreement among 118 nations was made on November 4, 2016 [1], known as the Paris Agreement on environment pollution, to combat climate change. According to this agreement, each country agreed to take measures to combat climate change, with the ultimate goal of keeping the post-industrial global temperature rise below two degrees Celsius. Carbon tax [2] is another

This paper was recommended for publication in revised form by Editor Orhan Canpolat

* Corresponding author/E-mail address: spaul.@metal.jdvu.ac.in (S.Paul)

https://doi.org/10.29187/jscmt.2021.58

Received 27 December 2018; Received in revised form 21 January 2020; Accepted 13 October 2020,

Available online 31 March 2021 
method is cut down gas emission. In this case individuals and companies will have to pay higher taxes higher pollution generation process but will get incentives if they conserve energy and pollute less.

The present investigation aims at utilizing $\mathrm{CO}_{2}$ and other harmful gases evolved in the atmosphere to produce useful products. That is waste to materials.

If $\mathrm{CO}_{2}$ is passed through water carbonic acid is formed according to the following reaction.

$$
\mathrm{CO}_{2}+\mathrm{H}_{2} \mathrm{O}=\mathrm{H}_{2} \mathrm{CO}_{3} \leftrightarrow 2 \mathrm{H}^{+}+\mathrm{CO}_{3}^{2-}
$$

Carbonic acid is produced and further by hydrolysis, acid is generated and $\mathrm{pH}$ decreases of the system. How to utilize these two products?

Chalcopyrite ore, $\mathrm{CuFeS}_{2}$, with $\mathrm{Cu}$ percentage less than $0.05 \%$ is not used for $\mathrm{Cu}$ production by conventional route. This low grade ore waste, obtained after mining and mineral beneficiation is dumped outside $\mathrm{Cu}$ extraction part and so only transportation cost is required to procure it.

Conventionally $\mathrm{Cu}$ is extracted from $\mathrm{CuFeS}_{2}$ by pyrometallurgical route [3,4], that is roasting and smelting, converting at high temperature, followed by Electrorefining. The first three processes generate another polluting gas $\mathrm{SO}_{2}$ which is thrown into the atmosphere and is the main culprit for acid rain. Instead, if the chalcopyrite ore CuFeS2 is hydrometallurgical extracted using by some solvent leachant [5], Sulphur will come as element sulphur $\mathrm{S}$, which can be sold as by-product generation of $\mathrm{SO}_{2}$ can be prevented. The reaction is as follows:

$$
\mathrm{CuFeS}_{2}+\mathrm{X}\left(\text { Lechant: } \mathrm{H}^{+}, \mathrm{Fe}^{3+}\right) \rightarrow \mathrm{Cu}^{2+}+\mathrm{Fe}^{2+}+2 \mathrm{~S}
$$

The reaction requires highly oxidizing condition to be maintained. $\mathrm{Fe}^{3+}$ is an oxidizing agent, but it reduces to $\mathrm{Fe}^{2+}$ after the reaction. To find the feasibility to utilize the green gas (1) for the above extraction of $\mathrm{Cu}(2)$, the reactions (1) and (2) need to be combined as follows:

$$
\mathrm{CuFeS} 2+4 \mathrm{H}^{+}+2 \mathrm{CO}_{3}^{2-} \rightarrow \mathrm{Cu}^{2+}+\mathrm{Fe}^{2+}+2 \mathrm{~S}+2 \mathrm{H}_{2}+2 \mathrm{CO}_{3}^{2-}
$$

Since $\mathrm{Cu} / \mathrm{Cu}^{2+}$ system is more noble than $\mathrm{H}_{2} / \mathrm{H}^{+}$system, the reaction is feasible under oxidizing condition. $\mathrm{Fe}^{3+}$, an oxidizing agent, can be added to proceed the reaction to the forward direction, else the system can electrical oxidized by applying external potential to drag electron through electrode as discussed below.

\subsection{Combining Hydro and Electro Metallurgical Process}

In this concept [6], two conducting neural electrodes such as graphite are placed into the hydrometallurgical reactor. The one which acts as anode generates electron, producing oxidizing condition by the following reaction:

$$
\mathrm{Fe}^{2+}-\mathrm{e}=\mathrm{Fe}^{3+}
$$

So the $\mathrm{Fe}^{2+}$ generated from the reaction (3) is oxidized back to $\mathrm{Fe}^{3+}$ by electrical oxidation ion the vicinity of anode.

At cathode $\mathrm{Cu}$ is deposited by the following reaction:

$$
\mathrm{Cu}^{2+}+2 \mathrm{e}=\mathrm{Cu}
$$

So the hydro and electro metallurgical processes occur simultaneously and in a single stage process $\mathrm{Cu}$ is produced. The applied potential and current from D C source works for oxidation at anode, favouring oxidizing condition in the vicinity of anode and reduction of $\mathrm{Cu}^{2+}$ to $\mathrm{Cu}$ at cathode for metal production. The potential should be controlled such that potential is sufficient to make reaction (5) occur but does not reduce $\mathrm{H}^{+}$to $\mathrm{H}$ and $\mathrm{Fe}^{2+}$ to Fe.

The reversible electrode potential required foe $\mathrm{Cu}$ deposition is given by Nernst equation as follows:

$$
\mathrm{E}_{\mathrm{re}}=\mathrm{E}_{0} \mathrm{M}+2.33 \mathrm{RT} / \mathrm{nF} \log [\mathrm{M}++]
$$


Where $\mathrm{M}$ stands for any metal $\mathrm{Cu} . \mathrm{E}_{0} \mathrm{M}$ is the standard electrode potential, $\mathrm{E}_{\mathrm{re}}$ is the reversible potential Cu electrode potential, $\mathrm{F}=$ faraday, $\mathrm{n}=$ no of the electrons involved. At anode the following reaction occurs and the product of it produce oxidizing condition for the reaction (3) to proceed

$$
\text { Anode } 2 \mathrm{H}_{2} \mathrm{O}=2 \mathrm{H}_{+}+\mathrm{O}_{2}+2 \mathrm{e}
$$

The applied potential is for $\mathrm{Cu}$ deposition is much more than given by the equation (6), since over voltages need to be added as given by the following equation:

$$
\mathrm{E}=\mathrm{E}_{\mathrm{eq}}+\eta_{\mathrm{act}}+\eta_{\mathrm{con}}+\mathrm{IR}_{\mathrm{elyt}}
$$

Where $\eta_{\text {act }}=$ Overvoltage due to activation polarization or charge transfer electrode reaction, $\eta_{\text {con }}$ overvoltage due to concentration polarization or mass transfer process by diffusion through the electrolyte, $R_{\text {elyt }}$ resistance of the electrolyte.

Generally, for electrodeposition, the conductivity of the bath is made very high and the $3^{\text {rd }}$ term of the equation may be neglected.

\section{Experimental Methods}

Low grade Chalcopyrite ore $(0.05 \% \mathrm{Cu})$ was obtained (Figure 1) from Hindustan Copper Limited, Ghatshila, Jharkhand India. It was crushed and ground t0 -200 mesh. $20 \mathrm{gm}$ of this ground ore was taken for each experiment. Polluting greenhouse gas $\mathrm{CO}_{2}$ was generated by dropping dilute $\mathrm{HCl}$ over $\mathrm{CaCO}_{3}$ as shown in Figure 2, experimental set up. Polluting gas was also produced by burning wood floor with air in an enclosed chamber as shown in the bottom part of Figure 2 . The real pollution environment was used in the next stage of experiments after $1^{\text {st }}$ set of experiment using pure $\mathrm{CO}_{2}$ was successful in producing $\mathrm{Cu}$.

The polluting gas was passed through the solution $(200 \mathrm{ml}$ distilled water), containing ground sample of $2 \mathrm{gm}$ Chalcopyrite ore. Two graphite electrodes were pushed through the top of the reactor and D C potential was applied across. The current and potential applied were recorded by digital meters. The electrode, connected with +ve terminal acted as anode and it helps in oxidizing leaching of the reaction 3 . The other electrode, connected with the -ve terminal acted as cathode where $\mathrm{Cu}$ was supposed to deposit from $\mathrm{Cu}^{2+}$ ions. Initially oxidizer $\mathrm{Fe}^{3+}$ ions were added to the solution to start the reaction.

\section{Results and Discussion}

The noble idea behind the present work is utilization of exhaust polluting gasses (mainly $\left.\mathrm{CO}_{2}\right)$ from the plant (Figure 1) and low grade unused chalcopyrite ore. Both are wastes which are converted to valuables. So the aim is waste to economy. Figure 2 shows the details of experimental set up which was discussed in the previous section.

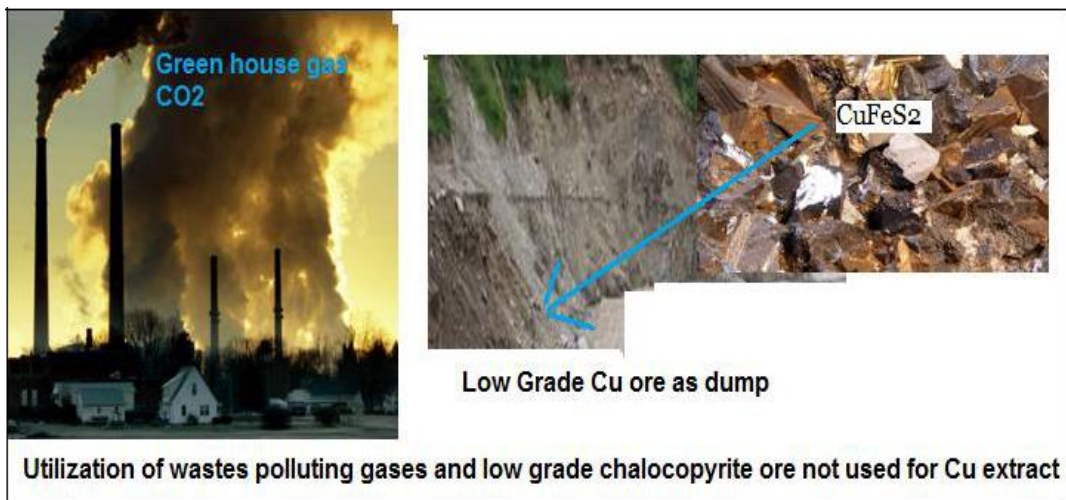

Figure 1. Emission of polluting $\mathrm{CO}_{2}$ gas used to produce $\mathrm{Cu}$ collected from waste 


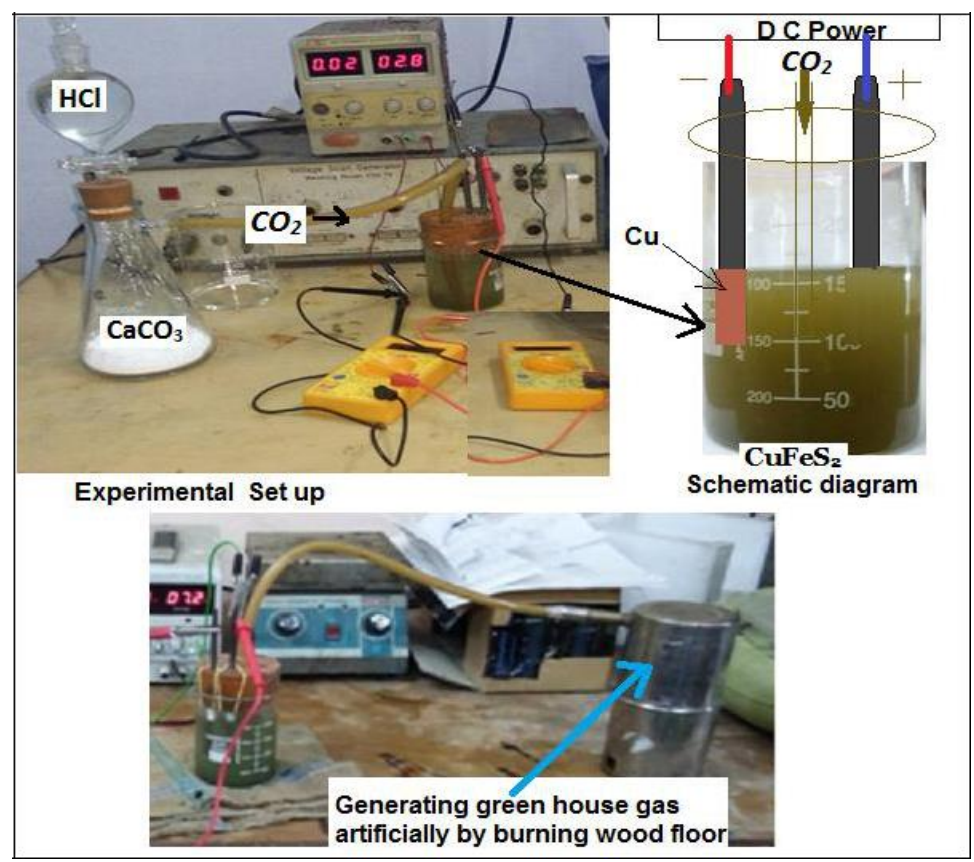

Figure 2. Experimental set up to extract $\mathrm{Cu}$, using $\mathrm{CO}_{2}$ generated from carbonate or Burning wood floor, by combined Hydro and Electro Metallurgical Process

It was found that after the experiment, the color of the solution turns yellow (Figure 3). This is due to release of elemental sulphur S as explained by the reactions (2) and (3) above. The solution was filtered and the residue (Sulphur) was dried to obtain sulphur as by-product. In the conventional process of $\mathrm{Cu}$ extraction from $\mathrm{CuFeS}_{2}$, sulphur comes out as $\mathrm{SO}_{2}$ gas which is thrown into the atmosphere, aggravating environment pollution. In the present process, not only this pollution problem is prevented, but sulphur comes out as product to sell and increase economy.

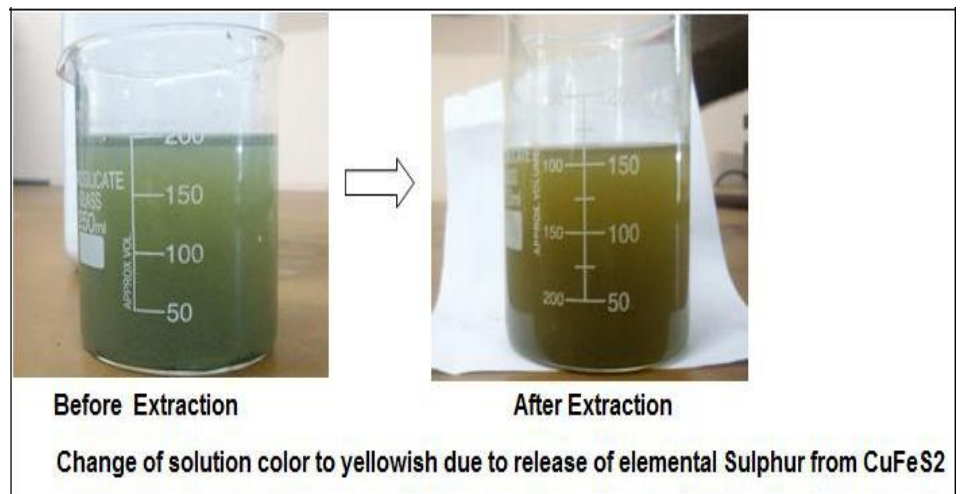

Figure 3. Showing yellowish solution due to release of elemental Sulphur

Figure 4 shows the $\mathrm{Cu}$ extracted at different temperature, both by hydrometallurgy and electrometallurgy. $\mathrm{Cu}^{2+}$ ions, first comes out from $\mathrm{CuFeS}_{2}$ into the solution by reacting with carbonic acid, produced from $\mathrm{CO}_{2}$ gas (reaction 3 ). This is hydrometallurgical extraction of $\mathrm{Cu}$. It requires an oxidizing condition. Initially it is provided by adding $\mathrm{Fe}^{3+}$ ions. But once the reaction starts, the anodic region gets oxidized as electrons are dragged through anode, with the reaction (4), when $\mathrm{Fe}^{3+}$ ions are regenerated, maintaining oxidizing condition at cathode the release $\mathrm{Cu}^{2+}$ ions are converted to metallic $\mathrm{Cu}$. Thus, when $\mathrm{Cu}$ extracted by hydrometallurgy falls, $\mathrm{Cu}$ extracted by electrometallurgy rises. 


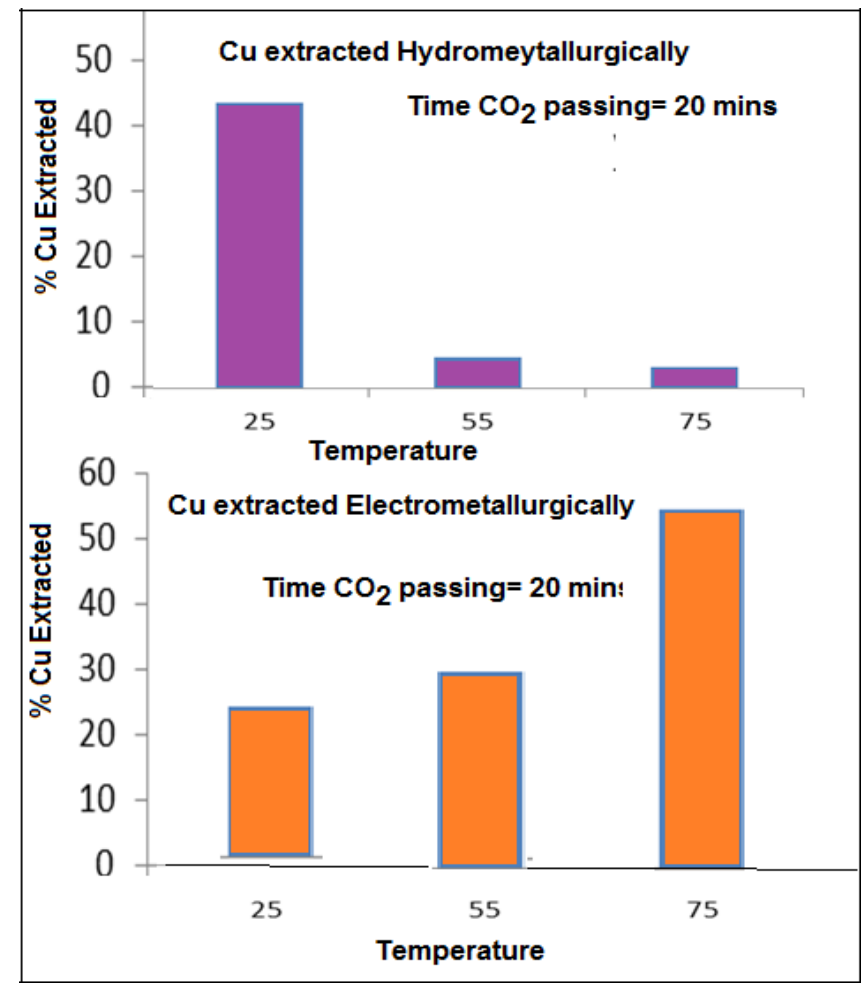

Figure 4. Bar graph showing metal extracted by Hydrometallurgy and Electro metallurgy with variation of temperature of leaching by $\mathrm{CO}_{2}$

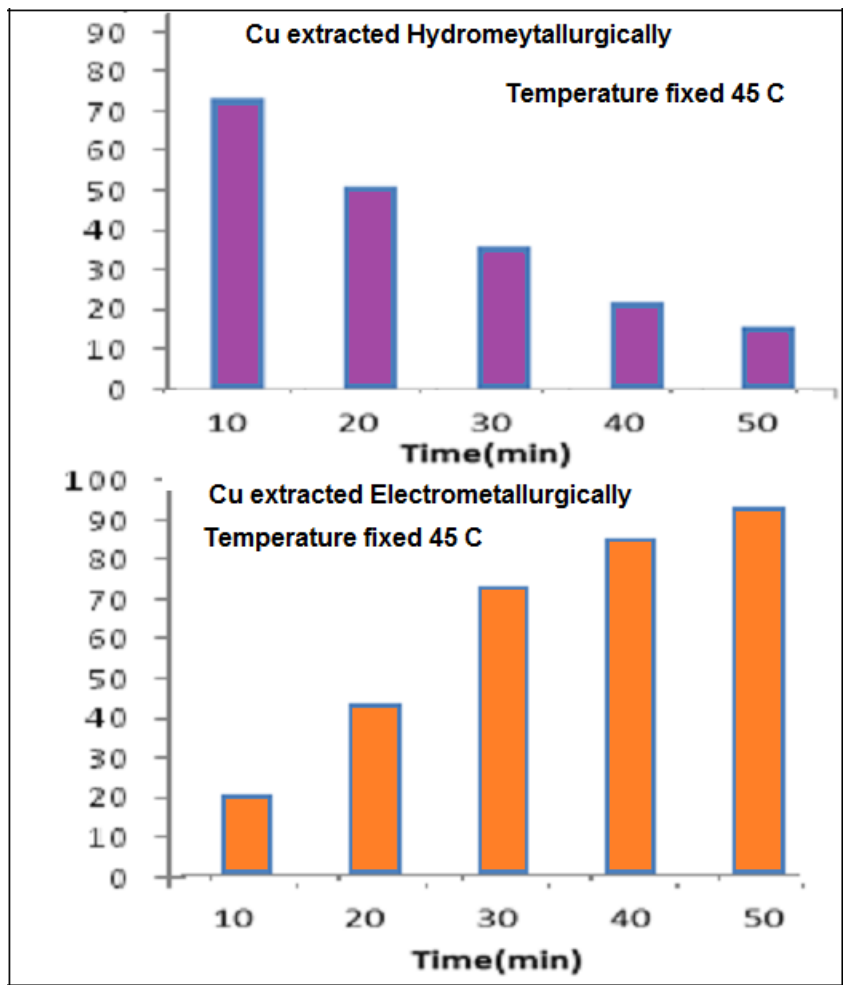

Figure 5. Bar graph showing metal extracted by Hydrometallurgy and Electrometallurgy with variation of the time of extraction by $\mathrm{CO}_{2}$

Figure 5 shows similar study as the function of time of $\mathrm{CO}_{2}$ gas passing, at fixed temperature of experiments.

The bar shows at each time (say $30 \mathrm{~min}$.), the addition of two bars values will give the total amount of $\mathrm{Cu}$ extracted during that time by the combined hydro and electrometallurgical process.

This is illustrated in Figure 6 which shows combined hydro and electro metallurgical extraction of $\mathrm{Cu}$ (green line curve) with passage of $\mathrm{CO}_{2}$ passing. It is seen that with passage of time the $\mathrm{Cu}$ amount by hydrometallurgy decreases, while that by 
electrometallurgy increases. So the $\mathrm{Cu}^{2+}$ released by hydrometallurgy is immediately deposited at graphite cathode. The XRD of the deposited $\mathrm{Cu}$ at cathode is shown in Figure 7, which exhibits the presence of $\mathrm{Cu}$, along with some $\mathrm{CuO}$.

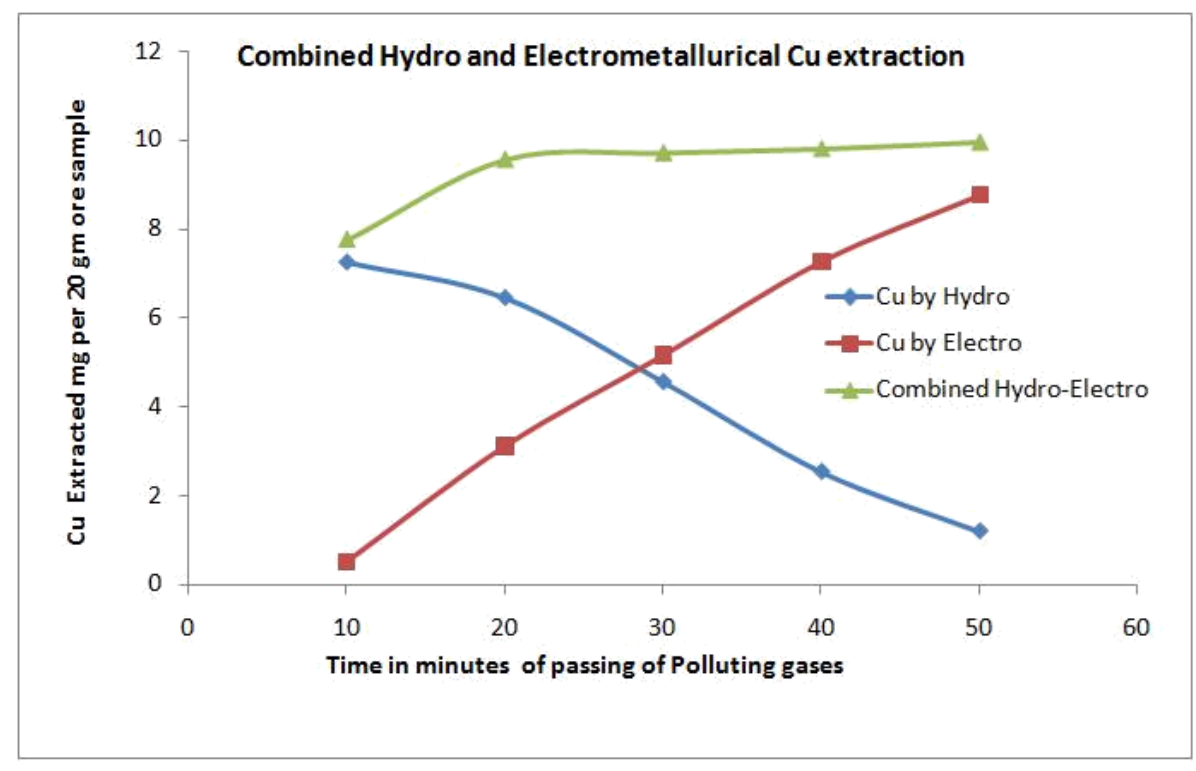

Figure 6. Comparison of $\mathrm{Cu}$ Extracted by Hydrometallurgy, Electrometallurgy and combined

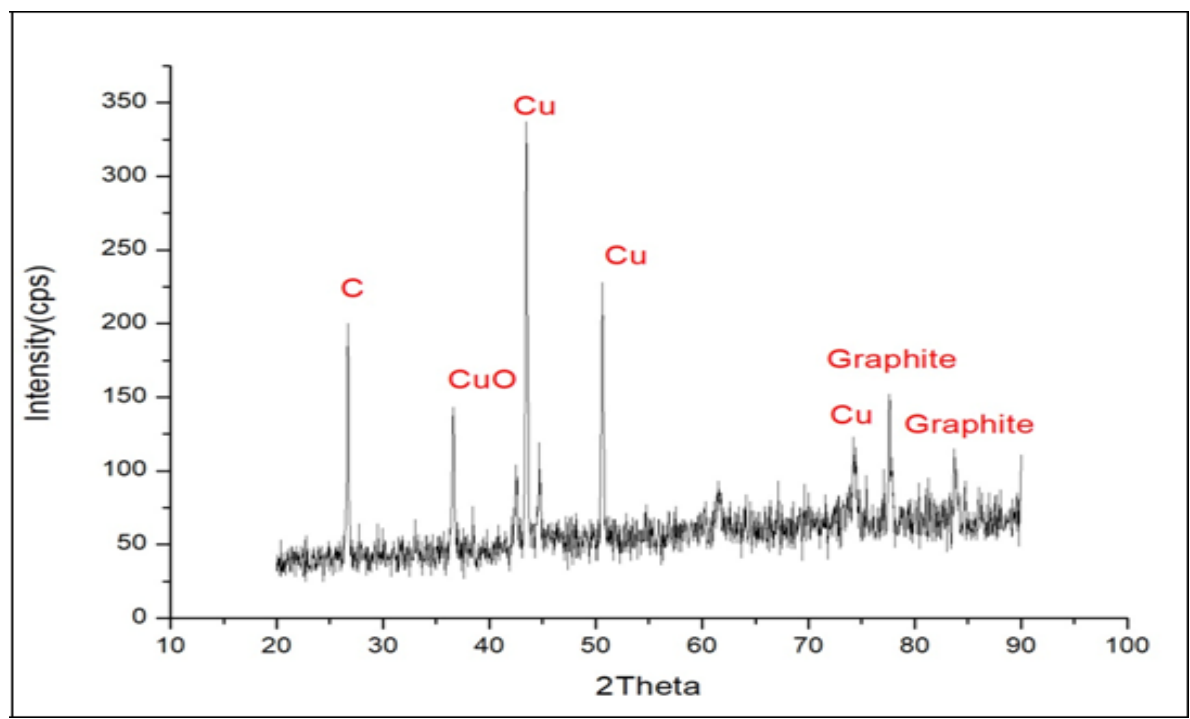

Figure 7. XRD of Electrodeposited $\mathrm{Cu}$

The applied potential between the two electrodes was 2.0-3.0 volt, depending on the temperature of operation and the applied current density was $3-5 \mathrm{~mA} / \mathrm{cm}^{2}$. Figure 8 shows the power consumption and energy required for Cu production by combined hydro and electro metallurgical process using the greenhouse gas. 


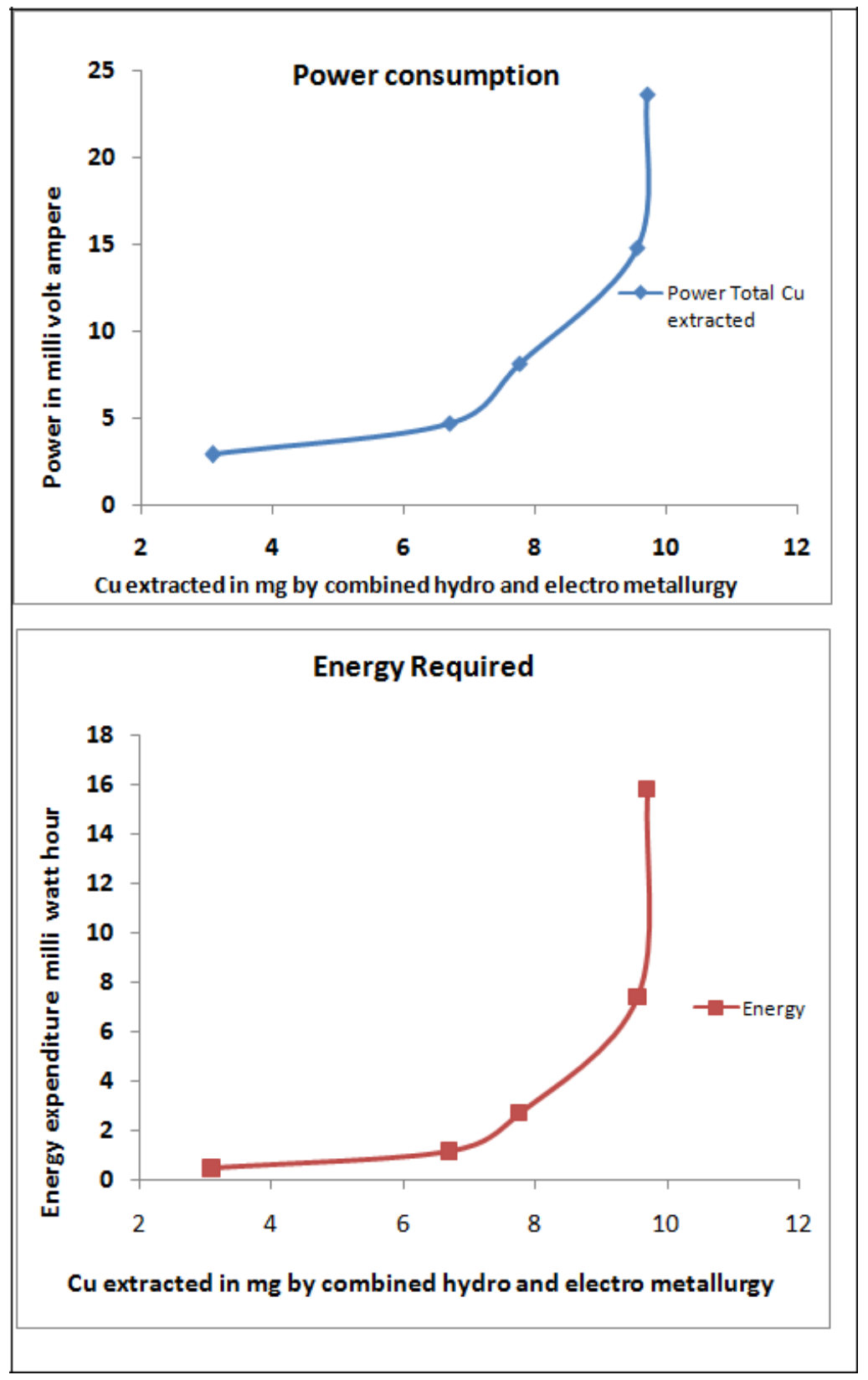

Figure 8. Power and energy consumption of amount of extracted $\mathrm{Cu}$

\section{Conclusion}

$\mathrm{Cu}$ production could be achieved from low grade $\mathrm{Cu}$ ore, using environment polluting greenhouse gases with an energy intensive process of a single stage combined hydro and electro metallurgical process.

\section{Conflict of interest}

The authors declared no potential conflicts of interest with respect to the research, authorship, and/or publication of this article

\section{Ethics}

There are no ethical issues after the publication of this manuscript. 


\section{References}

[1] Egypt, M. (2001) Multipurpose Forest Management Plans Based on Geographic Information Systems Purpose Programming Method (Forestry Planning Planning Example), Ph.D. Thesis, KTU Graduate School of Natural and Applied Sciences, Trabzon.

[2] Akay, A. E., Erdas, O., Belen, B. (2006). Using GIS-Based Sediment Estimation Model, SEDMODL2 in Calculation of Sediment from Forest Roads. Workshop made of forestation and erosion control applications in semi-arid regions of Turkey.

[3] Altun, L., Yilmaz, M., Acar, C., Turna, I., Başkent, E. Z., \& Bilgili, E. (2003). Evaluating the seasonal changes of water quality of the Değirmendere and Galyan Rivers (Trabzon, Turkey). Journal of Environmental Biology, 24(4), 415-422.

[4] Başkent, E. Z. (2001). Combinatorial optimization in forest ecosystem management modeling. Turkish Journal of Agriculture and Forestry, 25(3), 187-194.

[5] ETABS V13. Computers and structures Inc. New York, NY 10036, USA

[6] ACI 209R-08. (2008). Guide for Modelling and Calculating Shrinkage and Creep in Hardened Concrete. American Concrete Institute, USA. 